\title{
Polibotánica
}

ISSN electrónico: 2395-9525

POLIBETÁNICA

polibotanica@gmail.com

Instituto Politécnico Nacional México

http:www.polibotanica.mx

\section{PRINCIPIO DE CONSERVACIÓN: COEXISTENCIA ENTRE DIVERSIDAD DE ESPECIES COMESTIBLES Y CONOCIMIENTO TRADICIONAL}

\section{PRINCIPLE OF CONSERVATION: COEXISTENCE BETWEEN DIVERSITY OF EDIBLE SPECIES AND TRADITIONAL KNOWLEDGE}

Jasso-Arriaga, $X$.

PRINCIPIO DE CONSERVACIÓN: COEXISTENCIA ENTRE DIVERSIDAD DE ESPECIES COMESTIBLES Y CONOCIMIENTO TRADICIONAL.

PRINCIPLE OF CONSERVATION: COEXISTENCE BETWEEN DIVERSITY OF EDIBLE SPECIES AND TRADITIONAL KNOWLEDGE.

\section{POLIBETÁNICA}

Instituto Politécnico Nacional
Núm. 47: 179-199 México. Enero 2019

DOI: $10.18387 /$ polibotanica.47.13 


\section{PRINCIPIO DE CONSERVACIÓN: COEXISTENCIA ENTRE DIVERSIDAD DE ESPECIES COMESTIBLES Y CONOCIMIENTO TRADICIONAL}

\section{PRINCIPLE OF CONSERVATION: COEXISTENCE BETWEEN DIVERSITY OF EDIBLE SPECIES AND TRADITIONAL KNOWLEDGE}

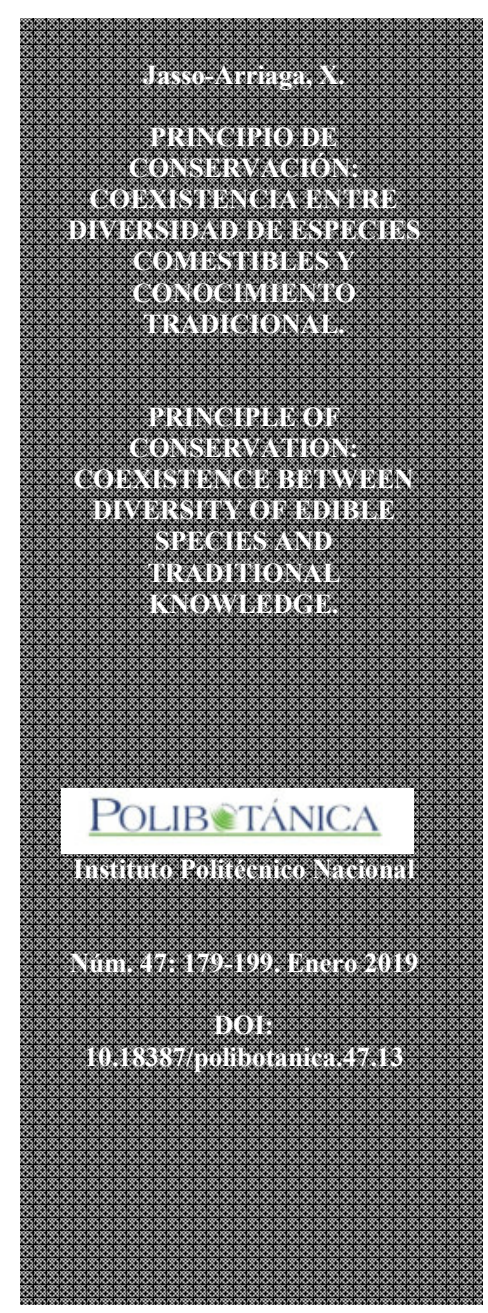

\author{
X. Jasso-Arriaga/ xjasso4@yahoo.com.mx \\ Universidad Autónoma del Estado de México. \\ Campus: Centro Universitario Temascaltepec \\ Carr. Toluca - Tejupilco Km. 67.5, Barrio de Santiago, \\ 51300 Temascaltepec de González, Méx.
}

RESUMEN: Se analizaron las variables que justifican la conservación del bosque y la milpa a través del conocimiento tradicional. Las entrevistas semi-estructuradas evidenciaron tres variables que se relacionan con la seguridad alimentaria y tres con la soberanía alimentaria en el marco de un listado de especies proporcionadas por los entrevistados. Las variables fueron codificadas y analizadas por medio de la correlación de Pearson y regresión logística para identificar las variables que prevén alimentos locales. La utilidad tradicional y la disponibilidad física explican el éxito de la soberanía alimentaria a partir de 84 especies comestibles localizadas en el bosque y en la milpa. Esta coexistencia da lugar al bienestar socioecológico de los pueblos ancestrales a partir de la conservación del ecosistema.

Palabras clave: conocimiento tradicional; especies; bosque; milpa; animales de traspatio; soberanía alimentaria.

ABSTRACT: The variables that justify the conservation of the forest and the milpa through traditional knowledge were analyzed. The semi-structured interviews showed three variables that relate to food security and three to food sovereignty within the framework of a list of species provided by the interviewees. The variables were coded and analyzed by means of the Pearson correlation and logistic regression to identify the variables that foresee local foods. Traditional utility and physical availability explain the success of food sovereignty from 84 edible species located in the forest and in the milpa. This coexistence gives rise to the socio-ecological well-being of the ancestral peoples from the conservation of the ecosystem.

Key words: traditional knowledge; species; forest; milpa; backyard animals; food sovereignty.

\section{INTRODUCCIÓN}

La agricultura industrial hoy en día es un modelo agotado, porque falló en asegurar una producción de alimentos para todas las personas, estableció la suposición de que siempre habría abundante agua y energía barata y que el clima no cambiaría, sin embargo las condiciones climáticas extremas son más comunes y violentas, amenazando los cultivos, especialmente los monocultivos modernos genéticamente homogéneos que cubren el $80 \%$ de las 1.500 millones de hectáreas de tierra cultivable, además la agricultura industrial contribuye con el $25-30 \%$ de las emisiones de gases efecto invernadero, modificando tendencias climáticas y comprometiendo así la capacidad de los sistemas productivos para prever alimento en el futuro 
(Altieri \& Nicholls, 2013). A este fenómeno se suma que las generaciones contemporáneas de pueblos ancestrales han abandonado prácticas milenarias sustentables, como es la milpa, en donde se reproducía la agrobiodiversidad (Bartra, 2008), está formaba parte del sustento alimenticio durante las cuatro estaciones del año.

A partir del siglo XX, México ha anclado su crecimiento económico en la explotación antiresiliencia de los recursos naturales (Tafoya, 2012; Leff, 2000), dando como resultado el incremento de tasas de agotamiento de la biota (Trombulak, et al., 2004). La cual, por milenios ha sido la base del sustento integral de pueblos ancestrales (Leff, 2000; Toledo, 1990), por consiguiente, conservaban los ecosistemas naturales y la reproducían a través de técnicas etnoecológicas. La biodiversidad la concebían como riqueza natural compartida, en consecuencia, era un bien común y sin valor económico. Una vez que se asignó y adquirió valor monetario, hubo mayor presión en su continuidad y con esto el incremento de la extracción y agotamiento de miles de especies (Gerez \& Purata, 2008).

La agricultura industrial fomentada por la aldea global y que además cada una de sus acciones de preponderancia homogeneiza, fragmenta, totaliza y parcializa a los países sin reconocer la diversidad cultural de sus pueblos ancestrales (Pradilla, 1996; Leff, 2000), dando como resultado el incremento de la marginación y degradación de ecosistemas. El concepto de conservación simbiótica reconoce que la diversidad biológica y la cultura son mutuamente dependientes y geográficamente coexistentes (Nietschmann, 1992). Constituye un principio clave para la teoría de la conservación y sus aplicaciones, además epistemológicamente es una expresión de la nueva investigación integradora e interdisciplinaria (Toledo, Boege \& BarreraBassol 2010). Los pueblos ancestrales son agentes activos generadores de biodiversidad, porque han seleccionado y domesticado miles de vegetales, destacando las variedades tradicionales que están adaptadas a las necesidades culturales y condiciones ambientales propias de cada lugar, estas constituyen el patrimonio cultural y biológico, y que han asegurado la autosuficiencia y soberanía alimentaria, pero en las últimas décadas las variedades tradicionales están siendo sustituidas por variedades comerciales mejoradas en centros de investigación o por compañías de semillas que generalmente son más productivas, pero con una diversidad genética mucho menor que las variedades tradicionales (Pardo de Santayana, et al., 2012). El concepto de seguridad alimentaria apareció en los años setenta y determina el acceso a los alimentos en forma cuantitativa y cualitativa (Heinisch, 2013), posteriormente, la soberanía alimentaria es un concepto que introdujo la Vía Campesina en la Cumbre contra el Hambre de la FAO en 1996, aborda el derecho de cada pueblo a definir sus propias políticas agropecuarias y de producción de alimentos, así como defender la opción de formular aquellas políticas y prácticas comerciales que mejor sirvan a los derechos de la población a disponer de alimentos inocuos, nutritivos y ecológicamente sustentables e integra las condiciones de acceso a los alimentos y los modos de definición de esas condiciones, en aspectos económico, ecológico y social (Rosset, 2003; Heinisch, 2013). La seguridad y soberanía alimentaria son complementarios (Heinisch, 2013). Para la presente investigación se retomará de la seguridad alimentaria la disponibilidad, accesibilidad y utilidad de especies comestibles silvestres y cultivadas en forma cuantitativa. De la soberanía alimentaria se retomará la condición socio-ecológico para el acceso de las especies comestibles silvestres y cultivadas, a través del conocimiento ecológico tradicional, este tiene su origen en la etnoecología.

La soberanía alimentaria constituye la forma evolucionada, ampliada o complementaria del concepto de seguridad alimentaria, además analiza variables cualitativas, como la otredad, cultura de pueblos, conservación de recursos naturales y bienestar, en donde se consideran las relaciones sociales libres de presión y desigualdades (Almeida \& Scholz, 2008), la clave es la práctica del conocimiento tradicional desarrollado en la milpa, en el patio y en el manejo de la biodiversidad de especies silvestres y cultivadas que aportan tres principios de gran relevancia, y que son: la soberanía alimentaria, la medicina y la cultura material e inmaterial (Levy, Aguirre, Martínez \& Durán, 2002), de forma que el objetivo de la presente investigación consiste en analizar las variables que justifican la conservación del bosque y la milpa a través 
del conocimiento tradicional en San Antonio Acahualco. Se pretende retomar y revalorizar el conocimiento ecológico tradicional para la conservación del ecosistema, porque la coexistencia de ambos es el fundamento primordial para lograr el bienestar socio ecológico.

\section{MÉTODOS}

Área de estudio. La investigación se realizó en San Antonio Acahualco, es una localidad del municipio de Zinacantepec, Estado de México, se localiza entre las coordenadas extremas de latitud norte a $19^{\circ} 27^{\prime} 69^{\prime \prime}$ y a 99 $77^{\prime} 56^{\prime \prime}$ longitud oeste. Se localiza al suroeste de la Zona Metropolitana de la Ciudad de Toluca a unos 45 minutos (fig. 1). Su altitud es de $2811 \mathrm{~m}$ s.n.m., su clima es semifrío subhúmedo con una temperatura máxima promedio de $22^{\circ} \mathrm{C}$ y una temperatura mínima promedio de $6^{\circ} \mathrm{C}$ (INEGI, 2010).

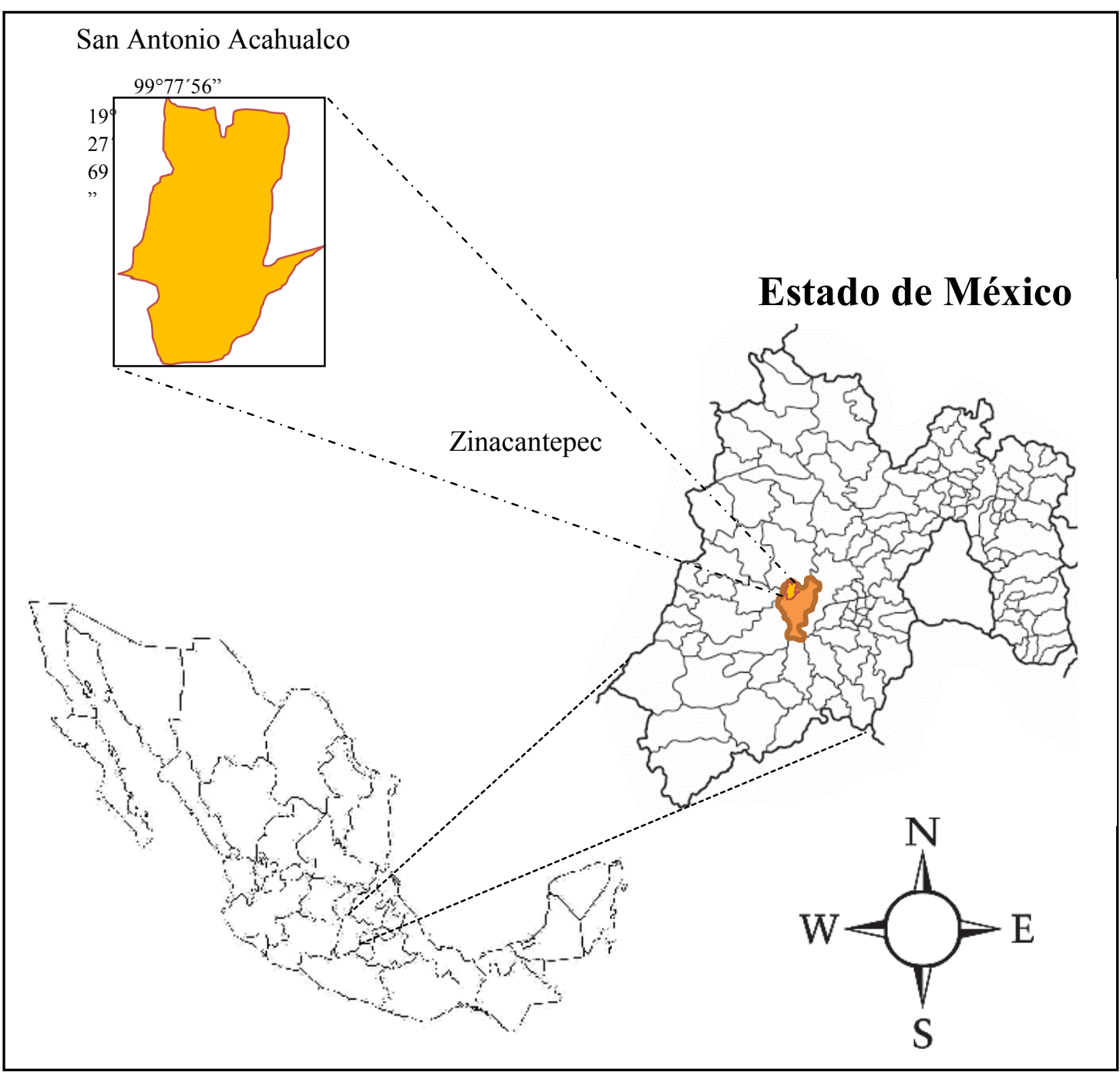

Fig. 1. Localización de San Antonio Acahualco, localidad de Zinacantepec. 
Recolección de datos. El método de investigación utilizado es el exploratorio, para el registro del conocimiento tradicional o el conocimiento ecológico tradicional. Se utilizó el muestreo no probabilístico intencional-consecutivo. Se aseguró que la población que posee el conocimiento tradicional sea nativa del lugar, y que sea reconocida por la población local; como personas con sabiduría ancestral sobre especies comestibles. Se obtuvo un listado de 61 personas, pero sólo 12 estaban en buena condición física y con disposición en darnos una entrevista voluntaria.

La entrevista semiestructurada fue determinada a partir de preguntas abiertas con respecto a las especies comestibles que conocen, conocimiento pasado y presente de su uso, partes usadas, los métodos de su preparación y consumo, lugar y fechas de recolección dentro del bosque y entre la milpa (Signorini, Piredda \& Bruschi, 2009). La entrevista inició con una presentación del investigador, se mencionó el objetivo de la entrevista, sobre el registro del conocimiento tradicional con respeto a las especies comestibles. Adicionalmente se explicó que la información obtenida seria empleada para fines académicos. Se cuidó la forma de preguntar, se utilizó lenguaje apropiado junto con una actitud de escucha y respeto (Signorini, Piredda \& Bruschi, 2009). Las entrevistas fueron grabadas con permiso de los informantes, cuando no era permitido, se utilizó un diario en donde se recuperó la información. Una vez finalizada la entrevista se agradeció la atención recibida.

La entrevista semiestructurada arrojó un listado de 84 especies comestibles, además los entrevistados evidenciaron tres variables que se relacionan con la seguridad alimentaria y tres con la soberanía alimentaria. El listado fue utilizado para una segunda entrevista estructurada con preguntas codificadas de acuerdo con la información proporcionada en la entrevista semiestructurada. La disponibilidad fue cuantificada por la presencia física de la especie y fue codificada dicotómicamente, es decir, 1 = para las especies estacionales, 2 = especies presentes durante todo el año. La variable accesibilidad fue considerada como la factibilidad de acceder a la especie y fue codificada a escala tipo Likert, $3=$ para las especies silvestres, $2=$ silvestrescultivadas, $1=$ cultivadas. $Y$ la variable $u$ tilidad fue codificada de acuerdo a la capacidad de la especie para satisfacer la necesidad alimentaria: $4=$ muy alta, $3=$ alta, $2=$ media y $1=$ baja. El número de los diferentes usos (NC) se contabilizó la cantidad de formas mencionadas de preparación para su consumo. Para el número de reportes (NR) se consideró la parte de la planta utilizada, indicación detallada de la preparación, las fechas que están disponibles para su consumo e indicaciones de consumo durante el día. Por último, se contabilizó el número de informantes que mencionó la especie (FC).

El siguiente paso fue la concentración de información de la tabla 1 y 2 (Dis = disponibilidad, Acc $=$ accesibilidad, $\mathrm{Uti}=$ utilidad, $\mathrm{FC}=$ número de informantes que mencionó la especie, $\mathrm{NC}$ = número de los diferentes usos y $\mathrm{NR}=$ número de reportes) en una base de datos de Excel. Subsiguientemente se utilizó en el paquete estadístico IMB SPSS Statistics, versión 17. Las variables fueron sometidas estadísticamente, a través de la correlación de Pearson y se identificó la correspondencia entre variables que sustentan la hegemonía de alimentos locales producto del bosque y la milpa. También se realizó el modelo de regresión logístico, a través de dicho paquete estadístico, en donde, la variable dependiente fue la soberanía alimentaria, las variables explicativas fueron: la utilidad, acceso y disponibilidad de las especies (seguridad alimentaria). Una vez que se obtuvo la $b_{0}, b_{1} \ldots b_{n}$ de las variables explicativas y de la constante se sustituyó la siguiente fórmula general de regresión logística, para identificar cual es la variable que más explica la soberanía alimentaria en función de las variables de seguridad, ya que ambas se complementan, pero la soberanía va más allá de la información cuantitativa, porque aborda el enfoque ecológico, económico y social de los alimentos locales:

$P(Y)=\frac{1}{1+e^{-\left(b_{0}+b_{2} X_{1}+b_{z} X_{2}+\cdots+b_{n} X_{n}+\varepsilon_{i}\right)}} \quad$ Fórmula (1) 
Donde: $\boldsymbol{P}$ es la probabilidad que ocurra $Y$ a partir de la fuerte cohesión de relaciones entre variables explicativas, $Y$ es la variable dependiente o explicada representada por la soberanía alimentaria, $e$ es la base del logaritmo natural, $\mathrm{b}_{0}$ es la constante (es la intercepción de la función de regresión $Y$ ), siendo $b_{1}, b_{2}$ y $b_{n}$ coeficientes de las variables explicativas, $X_{1}, X_{2}$ y $X_{n}$ son las variables independientes o explicativas (disponibilidad, accesibilidad y utilidad); $\varepsilon_{\mathrm{i}}$ término de perturbación o error. Los valores de las variables explicativas fueron corridas en el software SPSS y arrojó la viable o variables significativa(s) que explica(n) a la variable dependiente en términos de porcentaje, por consiguiente la fórmula 1 fué sustituida tomando los valores de $b_{0}$ y $b_{1}$ arrojados por el paquete estadístico, así como el valores de la variable (s) significativa (s) y $e$ es igual a 2.718 .

Se visitó el tianguis de San Antonio Acahualco, se adquirieron tres ejemplares de hongos comestibles silvestres conocidas por las 12 personas que poseen el conocimiento tradicional para su identificación taxonómica. Se realizaron las descripciones de los cuerpos fructíferos y se les tomaron fotografías en fresco. Su identificación se desarrolló, a partir de características macroscópicas y microscópicas. El estudio microscópico se basó en la observación de preparaciones hechas a partir de cortes de navaja, montados en hidróxido de potasio $(\mathrm{KOH})$ en solución acuosa al 15\% (Cifuentes, Villegas \& Pérez, 1986). Se consultaron claves taxonómicas. Posteriormente se deshidrataron y se depositaron en la Facultad de Ciencias de la Universidad Autónoma del Estado de México.

Las especies comestibles silvestres fueron recolectadas con la participación voluntaria de cinco informantes clave, se llenó su ficha descriptiva y se deshidrataron. Se determinaron las especies con ayuda de un experto en taxonomía. El estudio microscópico consistió en observaciones a partir de cortes de navaja, montados en agua y se apoyó en claves taxonómicas (Rzedowski, Rzedowski \& colaboradores, 2005). Los ejemplares fueron depositaron en la Facultad de Ciencias de la Universidad Autónoma del Estado de México.

\section{RESUltados}

Se registró que las personas que poseen el conocimiento ecológico tradicional de San Antonio Acahualco es una forma de vida; fue evidenciada a través de la praxis en la milpa, en los huertos y en la cría de animales de traspatio. Además, valoran al bosque como riqueza natural y establecen que se debe conservar porque, es fuente de vida, gracias a las especies comestibles, los manantiales y ojos de agua. E incluso el gozo del alma por medio del canto de las aves y los paisajes que alegran el amanecer de cada día.

Acahualco se deriva del término acahual y significa lugar de las flores amarillas y su población nativa es de origen otomí. La entrevista semiestructura registró que solo la población de más de 70 años aún recuerda algunas palabras y frases en el idioma otomí, el resto de la población ignora este idioma. Conjuntamente se registró que existe el abandono relativo de la práctica de la milpa y actividades tradicionales, y con esto el desvinculo con la naturaleza, así como tradiciones, mitos, creencias y alimentos locales. Las personas que posee el conocimiento tradicional señalaron varias veces con tristeza, la desventura alimentaria, la pérdida de identidad, el agotamiento de los recursos naturales como parte del patrimonio natural y la inseguridad social que se aproxima para sus futuras generaciones, más tienen la esperanza de que esta tendencia sea modificada. La población económicamente activa labora en la Zona Metropolitana de la Ciudad de Toluca en actividades del sector secundario y terciario, a pesar de esto, algunas familias campesinas conservan la milpa en complemento con la cría de animales de traspatio, albañilería, carpintería, comercialización y extracción de recursos forestales no maderables en forma etnoecológica; es decir, piden permiso al bosque, dejan semillas y solo recolectan lo que necesitan, como son los hongos y plantas útiles (medicinales, comestibles, ornamentales, culturales, jabonosas, recreativas, pintura y otras). 
Las personas que posee el conocimiento tradicional evidenciaron que la disponibilidad de los recursos útiles depende de la conservación del bosque, de la práctica de la milpa, de las estaciones del año y del ciclo de lluvias, mientras la accesibilidad depende de tener en posesión un área de suelo para la práctica de la milpa y localización y tipo de tenencia (ejidal o comunal) del bosque, mientras que la utilidad depende de la conservación del conocimiento tradicional, ya que este indica en donde se localizan los recursos útiles dentro del bosque y el manejo ecológico de la milpa, ya que esta imita a los ecosistemas naturales. Prueba de lo anterior, se registraron 62 especies silvestres comestibles que se localizan en el bosque y en la milpa tradicional en San Antonio Acahualco (tabla 1).

Tabla 1. Especies silvestres comestibles del bosque y milpa.

\begin{tabular}{|c|c|c|c|c|c|c|c|c|c|c|}
\hline Núm. & $\begin{array}{l}\text { Nombre } \\
\text { común }\end{array}$ & Nombre científico & Familia & Hábitat & $\stackrel{n}{a}$ & 迸 & تَّ & U & U & 点 \\
\hline 1 & $\begin{array}{l}\text { Hongo de } \\
\text { llano }\end{array}$ & Agaricus sp. & AGARICACEAE & bosque & 1 & 3 & 3 & 3 & 3 & 3 \\
\hline 2 & Pipilas & $\begin{array}{l}\text { Agaricus silvicola } \\
\text { (Vittadini) Peck }\end{array}$ & AGARICACEAE & bosque & 1 & 3 & 3 & 2 & 2 & 2 \\
\hline 3 & Tecomates & $\begin{array}{l}\text { Amanita grupo } \\
\text { caesarea (Scop.) } \\
\text { Pers. }\end{array}$ & AMANITACEAE & bosque & 1 & 3 & 3 & 5 & 6 & 6 \\
\hline 4 & Mantecadas & $\begin{array}{l}\text { Amanita rubescens } \\
\text { (Tulloss \& } \\
\text { Lindgren) }\end{array}$ & AMANITACEAE & bosque & 1 & 3 & 3 & 2 & 2 & 3 \\
\hline 5 & Quintoniles & Amaranthus spp. & AMARANTHACEAE & milpa & 1 & 3 & 3 & 7 & 7 & 13 \\
\hline 6 & Talayotes & $\begin{array}{l}\text { Matelea } \\
\text { nummularia } \\
\text { (Decne.) Woods }\end{array}$ & ASCLEPIADACEAE & milpa & 1 & 3 & 2 & 3 & 4 & 5 \\
\hline 7 & $\begin{array}{l}\text { Pansas o } \\
\text { semitas }\end{array}$ & $\begin{array}{l}\text { Boletus barrowsii } \\
\text { (Thiers \& A. H. } \\
\text { SM.) }\end{array}$ & BOLETACEAE & bosque & 1 & 3 & 4 & 8 & 9 & 11 \\
\hline 8 & Jalambos & $\begin{array}{l}\text { Boletus luridus } \\
\text { (Shaeffer) }\end{array}$ & BOLETACEAE & bosque & 1 & 3 & 3 & 4 & 5 & 5 \\
\hline 9 & Viejitas & $\begin{array}{l}\text { Suillus pungens } \\
\text { (Thiers \& A. H. } \\
\text { Sm.) }\end{array}$ & BOLETACEAE & bosque & 1 & 3 & 3 & 4 & 5 & 6 \\
\hline 10 & $\begin{array}{l}\text { Hongo } \\
\text { amarrillo }\end{array}$ & $\begin{array}{l}\text { Cantharellus } \\
\text { cibarius } \text { Fr. }\end{array}$ & CANTHARELLACEAE & bosque & 1 & 3 & 3 & 6 & 7 & 7 \\
\hline 11 & Lasos & Drymaria ssp. & CARYOPHYLLACEAE & milpa & 1 & 3 & 2 & 3 & 3 & 5 \\
\hline 12 & Romero & $\begin{array}{l}\text { Spergula arvensis } \\
\text { L. }\end{array}$ & CARYOPHYLLACEAE & milpa & 1 & 3 & 1 & 4 & 2 & 5 \\
\hline 13 & $\begin{array}{l}\text { Epazote de } \\
\text { perro }\end{array}$ & $\begin{array}{l}\text { Chenopodium } \\
\text { incisum Poir }\end{array}$ & CHENOPODIACEAE & milpa & 1 & 3 & 1 & 5 & 6 & 22 \\
\hline 14 & Pericón & $\begin{array}{l}\text { Tagetes lucida } \\
\text { Cav. }\end{array}$ & COMPOSITAE & milpa & 1 & 3 & 4 & 8 & 24 & 40 \\
\hline 15 & $\begin{array}{l}\text { Diente de } \\
\text { león o endivia }\end{array}$ & $\begin{array}{l}\text { Taraxacum } \\
\text { officinale } \mathrm{L} \text {. }\end{array}$ & COMPOSITAE & milpa & 1 & 3 & 2 & 3 & 3 & 11 \\
\hline 16 & $\begin{array}{l}\text { Espinaca } \\
\text { cimarrona }\end{array}$ & $\begin{array}{l}\text { Sonchus oleraceus } \\
\text { L. }\end{array}$ & COMPOSITAE & $\begin{array}{l}\text { milpa } \\
\text { bosque }\end{array}$ & 1 & 3 & 1 & 1 & 1 & 3 \\
\hline 17 & Te de Chivo & Cosmos sp. & COMPOSITAE & bosque & 1 & 3 & 2 & 1 & 2 & 2 \\
\hline
\end{tabular}




\begin{tabular}{|c|c|c|c|c|c|c|c|c|c|c|}
\hline Núm. & $\begin{array}{l}\text { Nombre } \\
\text { común }\end{array}$ & Nombre científico & Familia & Hábitat & $\stackrel{\mathscr{a}}{a}$ & 这 & 富 & $\bigcup_{\mathfrak{I}}^{U}$ & U & 孚 \\
\hline 18 & Coralejos & Psathyrella sp. & COPRINACEAE & bosque & 1 & 3 & 2 & 1 & 1 & 1 \\
\hline 19 & Corazones & Brassica campestris L. & CRUCIFERAE & milpa & 1 & 3 & 4 & 8 & 8 & 15 \\
\hline 20 & Nabos & Brassica campestris L. & CRUCIFERAE & milpa & 1 & 3 & 4 & 6 & 7 & 15 \\
\hline 21 & Berros & $\begin{array}{l}\text { Nasturtium } \\
\text { officinale } \mathrm{R} . \mathrm{Br} \text {. }\end{array}$ & CRUCIFERAE & $\begin{array}{l}\text { milpa } \\
\text { bosque }\end{array}$ & 1 & 3 & 2 & 3 & 4 & 8 \\
\hline 22 & $\begin{array}{l}\text { Trébol de } \\
\text { milpa }\end{array}$ & $\begin{array}{l}\text { Trifolium pratense } \\
\text { L. }\end{array}$ & FABACEAE & milpa & 1 & 3 & 4 & 1 & 1 & 2 \\
\hline 23 & $\begin{array}{l}\text { Cornetas } \\
\text { blancas }\end{array}$ & $\begin{array}{l}\text { Gomphus } \\
\text { kauffmanii (AH } \\
\text { Sm.) Corner } \\
\end{array}$ & GOMPHACEAE & bosque & 1 & 3 & 2 & 7 & 7 & 10 \\
\hline 24 & $\begin{array}{l}\text { Cornetas } \\
\text { amarillas }\end{array}$ & $\begin{array}{l}\text { Gomphus } \\
\text { floccosus (Schw.) }\end{array}$ & GOMPHACEAE & bosque & 1 & 3 & 3 & 1 & 1 & 2 \\
\hline 25 & Garrapatas & \begin{tabular}{|l|} 
Ribes \\
microphyllum \\
HBK \\
\end{tabular} & GROSSULARIACEAE & milpa & 2 & 3 & 2 & 2 & 3 & 2 \\
\hline 26 & Gachupines & $\begin{array}{l}\text { Helvella fusca } \\
\text { (Gillet) }\end{array}$ & HELVELLACEAE & bosque & 2 & 3 & 4 & 9 & 10 & 15 \\
\hline 27 & $\begin{array}{l}\text { Hongo blanco } \\
\text { o Sanjuanero }\end{array}$ & Hygrophorus sp. & HYGROPHORACEAE & bosque & 1 & 3 & 2 & 0 & 1 & 1 \\
\hline 28 & Cilantrillo & $\begin{array}{l}\text { Lilaea scilloides } \\
\text { (Poir.) Hauman }\end{array}$ & JUNCAGINACEAE & milpa & 1 & 3 & 1 & 1 & 1 & 1 \\
\hline 29 & Tabaquillo & Satureja sp. & LAMIACEAE & bosque & 1 & 3 & 4 & 4 & 5 & 10 \\
\hline 30 & Té de monte & $\begin{array}{l}\text { Lonicera mexicana } \\
\text { (Kunth) Rehder }\end{array}$ & CAPRIFOLIACEAE & bosque & 2 & 3 & 3 & 2 & 2 & 4 \\
\hline 31 & Salvia & $\begin{array}{l}\text { Buddleja perfoliata } \\
\text { HBK. }\end{array}$ & LOGANIACEAE & bosque & 1 & 3 & 1 & 3 & 4 & 9 \\
\hline 32 & Terneras & $\begin{array}{l}\text { Bovista aff. } \\
\text { aestivalis } \\
\text { (Bonord.) } \\
\text { Demoulin } \\
\end{array}$ & LYCOPERDACEAE & bosque & 1 & 3 & 3 & 2 & 2 & 2 \\
\hline 33 & Malvas & Malva parviflora L. & MALVACEAE & milpa & 1 & 3 & 4 & 7 & 11 & 21 \\
\hline 34 & Mazorcas & $\begin{array}{l}\text { Morchella } \\
\text { esculenta (Fries) }\end{array}$ & MORCHELLACEAE & bosque & 2 & 3 & 4 & 6 & 7 & 9 \\
\hline 35 & Huesitos & $\begin{array}{l}\text { Sarcosphaera } \\
\text { crassa (Santi) } \\
\text { Pouzar }\end{array}$ & PEZIZEACEAE & bosque & 1 & 3 & 2 & 1 & 1 & 1 \\
\hline 36 & Sanguinarias & $\begin{array}{l}\text { Polygonum } \\
\text { aviculare L. }\end{array}$ & POLYGONACEAE & milpa & 1 & 3 & 4 & 6 & 11 & 19 \\
\hline 37 & $\begin{array}{l}\text { Quelite de } \\
\text { perro }\end{array}$ & Rumex sp. & POLYGONACEAE & milpa & 1 & 3 & 1 & 5 & 5 & 16 \\
\hline 38 & $\begin{array}{l}\text { Quelite de } \\
\text { venado }\end{array}$ & $\begin{array}{l}\text { Claytonia } \\
\text { perfoliata } \text { ssp. } \\
\text { mexicana (Rydb.) } \\
\text { Mill. \& Chambers }\end{array}$ & PORTULACACEAE & bosque & 1 & 3 & 2 & 1 & 1 & 2 \\
\hline 39 & $\begin{array}{l}\text { Chivitos o } \\
\text { mutos }\end{array}$ & $\begin{array}{l}\text { Calandrinia ciliata } \\
\text { (Ruiz \& Pav.) DC }\end{array}$ & PORTULACÁCEAS & milpa & 1 & 3 & 4 & 6 & 6 & 10 \\
\hline 40 & Cenizos & $\begin{array}{l}\text { Chenopodium } \\
\text { berlandieri Moq. }\end{array}$ & QUENOPODIÁCEAS & milpa & 1 & 3 & 4 & 10 & 11 & 18 \\
\hline 41 & $\begin{array}{l}\text { Patita de } \\
\text { pájaro }\end{array}$ & $\begin{array}{l}\text { Ramaria flava } \\
\text { (Schaeffer) }\end{array}$ & RAMARIACEAE & bosque & 2 & 3 & 4 & 5 & 6 & 6 \\
\hline
\end{tabular}




\begin{tabular}{|c|c|c|c|c|c|c|c|c|c|c|}
\hline Núm. & $\begin{array}{l}\text { Nombre } \\
\text { común }\end{array}$ & Nombre científico & Familia & Hábitat & $\stackrel{\mathscr{a}}{0}$ & $e^{e}$ & $\stackrel{\circ}{\sigma}$ & U & Z & 妾 \\
\hline 42 & Capulin & $\begin{array}{l}\text { Prunus serotina } \\
\text { ssp. capuli (Cav.) } \\
\text { Mc Vaugh }\end{array}$ & ROSACEAE & milpa & 2 & 3 & 3 & 8 & 11 & 27 \\
\hline 43 & Tejocotes & Crataegus sp. & ROSACEAE & milpa & 2 & 3 & 3 & 8 & 10 & 24 \\
\hline 44 & Garambullo & $\begin{array}{l}\text { Rosa montezumae } \\
\mathrm{H} \& \mathrm{~B}\end{array}$ & ROSACEAE & milpa & 2 & 3 & 2 & 1 & 3 & 3 \\
\hline 45 & Zarza & Rubus sp. & ROSACEAE & $\begin{array}{l}\text { bosque } \\
\text { milpa }\end{array}$ & 1 & 3 & 2 & 1 & 1 & 1 \\
\hline 46 & Frambuesas & $\begin{array}{l}\text { Rubus pumilus } \\
\text { (Focke) }\end{array}$ & ROSACEAE & bosque & 1 & 3 & 1 & 5 & 1 & 1 \\
\hline 47 & Fresas & Fragaria vesca L. & ROSACEAE & bosque & 1 & 3 & 1 & 5 & 1 & 1 \\
\hline 48 & $\begin{array}{l}\text { Trébol de } \\
\text { bosque }\end{array}$ & $\begin{array}{l}\text { Didymaea aff. } \\
\text { alsinoides (Schlecht. } \\
\text { \& Cham.) Standl }\end{array}$ & RUBIACEAE & bosque & 1 & 3 & 4 & 5 & 8 & 16 \\
\hline 49 & Oreja blanca & $\begin{array}{l}\text { Russula brevipes } \\
\text { (Peck) }\end{array}$ & RUSSULACEAE & bosque & 1 & 3 & 4 & 7 & 8 & 8 \\
\hline 50 & Enchilados & $\begin{array}{l}\text { Lactarius } \\
\text { deliciosus (L. Fr.) } \\
\text { SF Gray }\end{array}$ & RUSSULACEAE & bosque & 1 & 3 & 4 & 4 & 5 & 5 \\
\hline 51 & Oreja Azul & $\begin{array}{l}\text { Lactarius indigo } \\
\text { (Schwein) Fr. }\end{array}$ & RUSSULACEAE & bosque & 1 & 3 & 2 & 1 & 1 & 1 \\
\hline 52 & Chipiles & Solanum sp. & SOLANACEAE & milpa & 1 & 3 & 2 & 3 & 4 & 4 \\
\hline 53 & $\begin{array}{l}\text { Jaltomateras } \\
\text { negras }\end{array}$ & $\begin{array}{l}\text { Jaltomata } \\
\text { procumbens (Cav.) } \\
\text { J.L.Gentry }\end{array}$ & SOLANACEAE & milpa & 1 & 3 & 2 & 3 & 3 & 4 \\
\hline 54 & Oscones & $\begin{array}{l}\text { Physalis } \\
\text { stapelioides } \\
\text { (Regel) Bitter }\end{array}$ & SOLANACEAE & milpa & 1 & 3 & 2 & 1 & 2 & 2 \\
\hline 55 & $\begin{array}{l}\text { Jaltomateras } \\
\text { verdes }\end{array}$ & Jaltomata $\mathrm{sp}$. & SOLANACEAE & milpa & 1 & 3 & 2 & 2 & 2 & 2 \\
\hline 56 & Escobeta & $\begin{array}{l}\text { Tremellodendropsis } \\
\text { sp. }\end{array}$ & $\begin{array}{l}\text { TREMELLADEN- } \\
\text { DROPSIDACEAE }\end{array}$ & bosque & 1 & 3 & 3 & 1 & 1 & 1 \\
\hline 57 & Clavos & $\begin{array}{l}\text { Lyophyllum } \\
\text { decastes (Fr.) } \\
\text { Singer }\end{array}$ & TRICHOLOMATACEAE & bosque & 1 & 3 & 4 & 10 & 11 & 11 \\
\hline 58 & Tejamalineros & $\begin{array}{l}\text { Clitocybe gibba } \\
\text { (Pers.) P. Kumm }\end{array}$ & TRICHOLOMATACEAE & bosque & 2 & 3 & 4 & 7 & 8 & 10 \\
\hline 59 & Cola de rata & $\begin{array}{l}\text { Tricholoma aff. } \\
\text { bufonium (Pers.) } \\
\text { Gille }\end{array}$ & TRICHOLOMATACEAE & bosque & 1 & 3 & 2 & 3 & 3 & 3 \\
\hline 60 & Julianas & $\begin{array}{l}\text { Tricholoma } \\
\text { populinum (J. E. } \\
\text { Lange) }\end{array}$ & TRICHOLOMATACEAE & bosque & 1 & 3 & 2 & 1 & 1 & 1 \\
\hline 61 & Hongo de jara & $\begin{array}{l}\text { Mycena leaiana } \\
\text { (Berkeley) } \\
\text { Saccardo }\end{array}$ & TRICHOLOMATACEAE & milpa & 1 & 3 & 1 & 1 & 1 & 2 \\
\hline 62 & Sanraje & $\begin{array}{l}\text { Hydrocotyle } \\
\text { ranunculoides L. }\end{array}$ & UMBELLIFERAE & $\begin{array}{l}\text { bosque } \\
\text { milpa }\end{array}$ & 1 & 3 & 1 & 4 & 5 & 11 \\
\hline
\end{tabular}

Dis $=$ Disponibilidad, Acc $=$ Accesibilidad, Uti $=$ Utilidad, $\mathrm{FC}=$ Número de informantes que mencionó la especie, $\mathrm{NC}=$ Número de los diferentes usos (categorías de uso secundarias), NR = Número de reportes (citaciones). 
Las especies comestibles de la tabla 1, son catalogadas por las personas que poseen el conocimiento tradicional a partir del kosmos-corpus-praxis, saben cuándo, cómo, en dónde y qué cantidades se debe recolectar. El periodo inicia a partir del ciclo de lluvia, y dan gracias a Dios, porque habrá disponibilidad de alimentos silvestres. Sólo recolectan en las primeras lluvias, 18 de marzo-mayo, en verano y al finalizar el ciclo. Antes de colectar cortan un manojo de hierbas aromáticas del bosque y limpian su aura, el propósito es para pedir permiso al bosque y para tener suerte en la colecta. Llevan un canasto de fibra natural para depositar las especies, solo cortan ramas tiernas y frutos en buen estado. Sólo colectan lo que comerán para un par de días, algunas especies son deshidratadas para la época de invierno y parte de la primavera. Identifican lugares específicos (hábitat ecológico) en donde se localizan las especies comestibles e inclusive diferencian el tipo de vegetación que está compuesto el bosque. Algunas especies las llaman por su hábitat ecológico, por ejemplo: hongo de zacatón, este es un tipo de pasto y se registraron tres especies y son: Muhlenbergia macroura (H. B. K.) Hitch, Stipa ichu (Ruiz \&Pavón) Kunth, y Piptochaetium virescens (Kunth) y el hongo que puede ser localizado es $C$. cibarius.

En el momento de recolectar la especie, principalmente hongos, sacuden el cuerpo fructífero en el lugar encontrado, posteriormente limpian el estípite o pie y píleo o sombrerillo, al final es depositado en el canasto, adicionalmente limpian sus manos en el musgo o herbáceas. Valoran el bosque como patrimonio de las presentes y futuras generaciones. Están en desacuerdo con la extracción del musgo (briofita), perlilla (Symphoricarpos microphyllus H. B. K.), zacatón (Muhlenbergia macroura (H. B. K.) Hitch, Stipa ichu (Ruiz \&Pavón) Kunth, y Piptochaetium virescens (Kunth) Parodi), jarrita morada (Penstemon gentianoides (Kunth) Poir, entre otros recursos forestales no maderables. Mencionan que tanto las hiervas y el musgo son la cobija del hongo, los arbustos y árboles les proporcionan sombra y humedad.

Para la recolección de las herbáceas comestibles siguen la técnica de solo cortar hojas, ramas tiernas sin flores, frutos, está prohibido extraer raíces, pero sobre todo dejan especies maduras para la siguiente temporada de lluvia. Estas especies sólo son recolectadas por temporada, ante esta situación, la población nativa, práctica la milpa y es considerada como el espacio ecológico para la reproducción y reservorio de especies para los meses que no hay presencia de especies silvestres, y sobre todo como herencia de sus ancestros, además conservan/manejan especies útiles silvestres, como los quelites, plantas medicinales, arbustos y árboles frutales (tabla 2).

Tabla 2. Especies cultivadas comestibles de la milpa

\begin{tabular}{|c|l|l|l|l|l|l|l|l|l|}
\hline Núm. & Nombre común & \multicolumn{1}{|c|}{ Nombre científico } & Familia & Dis & Acc & Uti & FC & NC & NR \\
\hline 63 & Maguey & Agave sp. & AGAVACEAE & 2 & 2 & 3 & 4 & 5 & 8 \\
\hline 64 & Hinojo & Foeniculum vulgare Mill. & $\begin{array}{l}\text { APIACEAE o } \\
\text { UMBELLIFERAE }\end{array}$ & 2 & 1 & 1 & 2 & 2 & 5 \\
\hline 65 & Nopal & $\begin{array}{l}\text { Opuntia ficus-indica } \text { L } \\
\text { (Mill.) }\end{array}$ & CACTACEAE & 1 & 1 & 3 & 2 & 2 & 6 \\
\hline 66 & Epazote & $\begin{array}{l}\text { Dysphania ambrosioides } \\
\text { (L.) Mosyakin \& Clemants }\end{array}$ & CHENOPODIACEAE & 1 & 2 & 1 & 4 & 4 & 7 \\
\hline 67 & Calabaza & Cucurbita sp. 1 & CUCURBITACEAE & 1 & 1 & 2 & 11 & 1 & 5 \\
\hline 68 & Chilacayote & Cucurbita sp. 2 & CUCURBITACEAE & 1 & 1 & 2 & 12 & 1 & 7 \\
\hline 69 & Habas & Vicia faba L. & FABACEAE & 2 & 1 & 4 & 10 & 1 & 6 \\
\hline 70 & Frijol & Phaseolus vulgaris L. & FABACEAE & 2 & 1 & 3 & 12 & 1 & 4 \\
\hline 71 & Hierbabuena & Mentha X piperita L. & LABIATAE & 2 & 1 & 1 & 7 & 10 & 25 \\
\hline 72 & Poleo & Cunila lythrifolia Benth. & LABIATAE & 2 & 2 & 1 & 5 & 7 & 15 \\
\hline 73 & Tomillo & Thymus vulgaris L. & LAMIACEAE & 1 & 1 & 1 & 2 & 2 & 4 \\
\hline
\end{tabular}




\begin{tabular}{|c|l|l|l|l|l|l|l|l|l|}
\hline Núm. & Nombre común & \multicolumn{1}{|c|}{ Nombre científico } & Familia & Dis & Acc & Uti & FC & NC & NR \\
\hline 74 & Romero & Rosmarinus officinalis L. & LAMIACEAE & 1 & 1 & 2 & 11 & 5 & 11 \\
\hline 75 & Laurel & Litsea glaucescens HBK. & LAURACEAE & 1 & 1 & 1 & 2 & 2 & 4 \\
\hline 76 & Higo & Ficus carica L. & MORACEAE & 2 & 1 & 1 & 1 & 1 & 4 \\
\hline 77 & Maíz & Zea mays L. & POACEAE & 2 & 1 & 4 & 2 & 2 & 7 \\
\hline 78 & Vinagreras & Rumex spp. & POLIGONÁCEAS & 1 & 2 & 2 & 4 & 4 & 8 \\
\hline 79 & Manzana & Malus domestica Borkh. & ROSACEAE & 2 & 1 & 2 & 4 & 5 & 16 \\
\hline 80 & Pera & Pyrus communis L. & ROSACEAE & 2 & 1 & 2 & 1 & 1 & 4 \\
\hline 81 & Durazno & Prunus persica (L) Batsch & ROSACEAE & 1 & 1 & 2 & 5 & 1 & 4 \\
\hline 82 & Ciruelo & Prunus sp. & ROSACEAE & 1 & 1 & 2 & 9 & 1 & 5 \\
\hline 83 & Chabacano & Prunus armeniaca L. & ROSACEAE & 1 & 1 & 2 & 3 & 1 & 4 \\
\hline 84 & Cedrón & Aloysia citriodora Palau & VERBENACEAE & 1 & 1 & 2 & 10 & 2 & 5 \\
\hline
\end{tabular}

Dis $=$ Disponibilidad, Acc $=$ Accesibilidad, Uti $=$ Utilidad, $\mathrm{FC}=$ Número de informantes que mencionaron la especie, $\mathrm{NC}=$ Número de los diferentes usos (categorías de uso secundarias), $\mathrm{NR}=$ Número de reportes (citaciones).

Anteriormente, la milpa estaba localizada a un lado o en la parte de atrás de las chozas. En la actualidad este espacio, está en proceso a cambio a uso habitacional. Las personas que todavía practican la milpa, la han desplazado hacia la periferia del pueblo, pero presenta una homogeneización biológica, en algunas milpas solo hay maíz y pasto (Pennisetum clandestinum Hochst. ex Chiov.).

El bosque y la milpa han proporcionado especies comestibles que por milenios han alimentado a la población nativa de San Antonio Acahualco, pero por su localización geográfica, en relación con la Zona Metropolitana de la Ciudad de Toluca, ha influido en el modo de vida sedentario y cambio en la dieta a base de recursos locales por alimentos adquiridos en el tianguis, mercado y supermercados y sobre todo han olvidado la importancia de producir sus propios alimentos a partir del kosmos-corpus-praxis de sus ancestros.

Se registraron fechas agrícolas importantes como: el 2 de febrero, día de la Candelaria y celebración de la bendición de las semillas locales, el 21 de marzo, fecha cuando se abre el ciclo de la siembra primavera-verano, a partir del 8 de julio al 28 de agosto, se prohíbe entrar a las milpas, para no alterar la polinización y está relacionada con el tiempo canicular, que tiene una duración de 40 días. Este período es considerado sagrado, explican que la tierra es más fértil, hay sanación de enfermedades, se define la buena cosecha y se cree que hay noches que las plantas comestibles crecen $10 \mathrm{~cm}$. El 14 de agosto se realiza la celebración del día de las cañas, fecha que se adornan las milpas con pericón (Tagetes lucida Cav.) y flores rojas del campo, además llevan las mejores cañas a las tumbas de sus antepasados, para conmemorar la celebración de la nueva cosecha de maíz. Anteriormente las cosechas iniciaban en los meses de octubre-noviembre, las personas que se adelantaban eran multadas. El sistema de la milpa está organizado por fechas de acuerdo a las estaciones del año para asegurar la cosecha anual. A finales de octubre y principios de diciembre cierran el ciclo de la cosecha y al término reparten el combate, consiste en dar dulces, galletas y cacahuates a los integrantes de la familia y a los peones agrícolas. Estas fechas reflejan la identidad de pertenencia a una comunidad, a buenas costumbres, a valores, a fomentar el bienestar y lograr la armonía con su entorno natural.

Otra de las actividades productivas de las personas que poseen el conocimiento tradicional es la cría de animales de traspatio, como son los guajolotes, gallinas, puercos, vacas, borregos, caballos y burros, además practican oficios como la albañilería, carpintería, comercio ambulante y se emplean como peones en actividades productivas agrícolas. Esto consolida aún más el asegurar sus propios alimentos (fig. 2). 


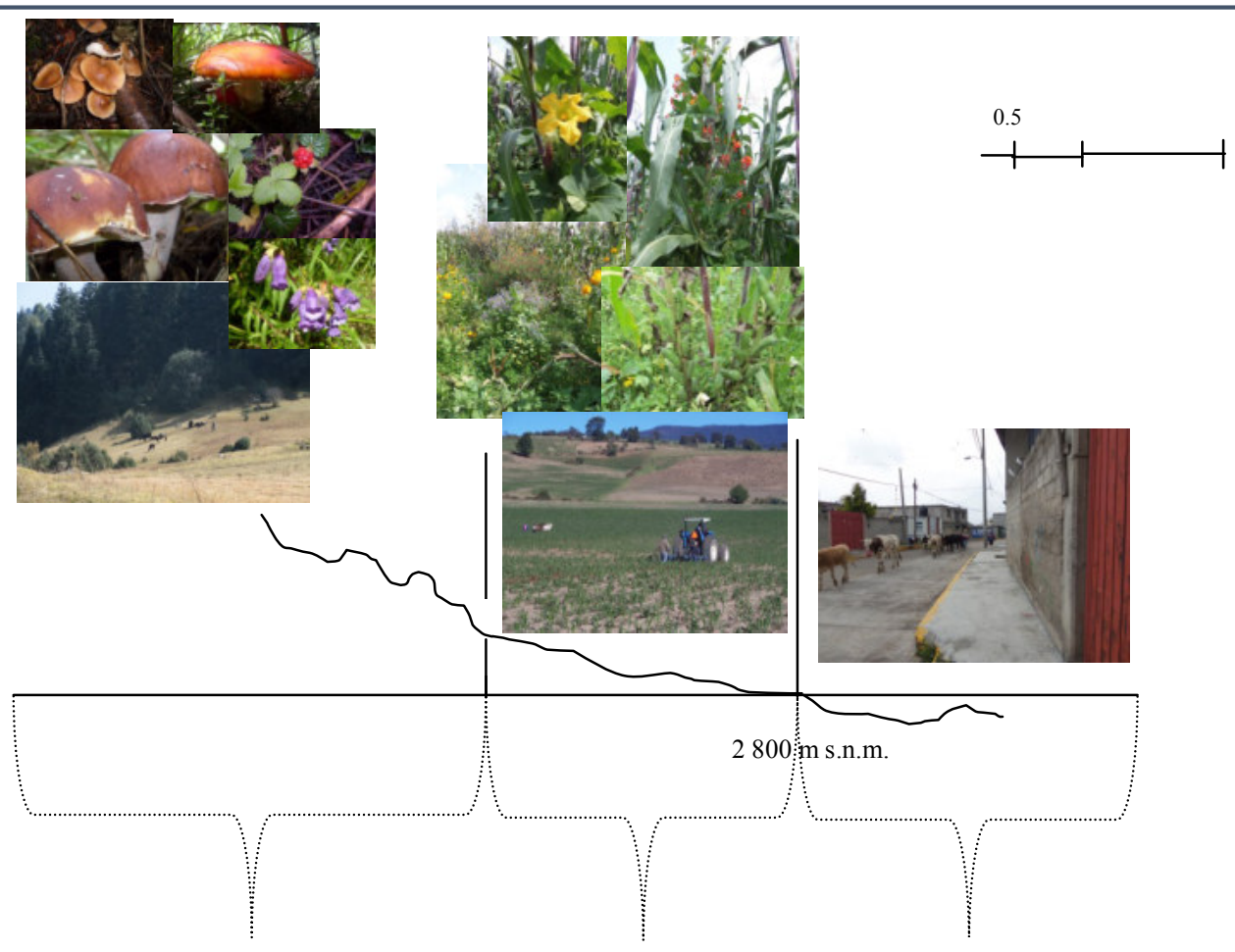

Bosque

Fig. 2. Bosque, milpa y animales de traspatio.

El alimento local de las familias campesinas es el resultado del kosmos, corpus y praxis de la etnoecología. El alimento local y está conformado por el maíz en complemento con especies silvestres y subproductos de animales de traspatio (tabla 3). Dando lugar a la diversidad de especies comestibles, que por cientos de años ha sido la base de su soberanía alimentaria.

La información de la tabla 1 y 2 sobre la Dis $=$ Disponibilidad, Acc $=$ Accesibilidad, Uti $=$ Utilidad, $\mathrm{FC}=$ Número de informantes que mencionaron la especie, $\mathrm{NC}=$ Número de los diferentes usos (categorías de uso secundarias), $\mathrm{NR}=$ Número de reportes (citaciones) se emplearon para calcular la correlación Pearson evidencia que la utilidad es la variable que más se relaciona con las variables de soberanía alimentaria (tabla 4), su explicación radica en la forma de como los habitantes nativos de San Antonio Acahualco se han apropiado de la naturaleza, los vínculos que han establecido, de una forma individual y al mismo tiempo en forma colectiva, lo que indica que el conocimiento tradicional es un medio de socialización y cohesión social, dando lugar, al forjamiento de la identidad alimentaria. 
Tabla 3. Especies silvestres y cultivadas.

\begin{tabular}{|c|c|c|c|c|c|c|c|c|c|c|c|c|}
\hline Silvestres/Cultivados & Ene & Feb & Mar & Abr & May & Jun & Jul & Ago & Sep & Oct & Nov & Dic \\
\hline Hongos & HD & HD & HD & HD & HD & $\mathrm{HF}$ & $\mathrm{HF}$ & $\mathrm{HF}$ & $\mathrm{HF}$ & $\mathrm{HF}$ & & \\
\hline Quelites & & & & & & $\mathrm{QF}$ & QF & $\mathrm{QF}$ & QF & & & \\
\hline Maíz & $\mathrm{T}$ & $\mathrm{T}$ & $\mathrm{T}$ & $\mathrm{T}$ & $\mathrm{T}$ & $\mathrm{T}$ & $\mathrm{TE}$ & $\mathrm{TE}$ & $\mathrm{T}$ & $\mathrm{T}$ & $\mathrm{T}$ & $\mathrm{T}$ \\
\hline Habas & HD & HD & HD & HD & HD & HD & $\mathrm{HF}$ & $\mathrm{HF}$ & $\mathrm{HF}$ & & & \\
\hline Frijoles & FD & FD & FD & FD & FD & FD & & & & & & \\
\hline Trigo & $\mathrm{TD}$ & TD & TD & TD & $\mathrm{TD}$ & TD & & & & & & \\
\hline Calabazas & & & & & & & $\mathrm{CF}$ & $\mathrm{CF}$ & $\mathrm{CF}$ & & & \\
\hline Chilacayote & & & & & & & $\mathrm{CF}$ & $\mathrm{CF}$ & $\mathrm{CF}$ & $\mathrm{CF}$ & & \\
\hline Nopales & & & & $\mathrm{N}$ & $\mathrm{N}$ & & & & & & & \\
\hline Leche y huevo & LH & LH & LH & LH & LH & LH & LH & LH & LH & LH & LH & LH \\
\hline
\end{tabular}

HD: hongos deshidratados, HF: hongos frescos, QF: quelites frescos, T: tortilla, TE: tortilla y elotes, HD: habas deshidratadas, HF: habas frescas, FD: frijoles deshidratados, TD: trigo deshidratado, CF: calabazas frescas, CHF: chilacayote fresco, N: nopales y LH: leche y huevo.

Tabla 4. Correlación Pearson.

\begin{tabular}{|c|c|c|c|c|c|c|c|}
\hline & & Utilidad & Accesibilidad & Disponibilidad & FC & NC & NR \\
\hline \multirow[t]{3}{*}{ Utilidad } & $\begin{array}{l}\text { Correlación de } \\
\text { Pearson }\end{array}$ & 1 & 0,035 & 0,088 & $0,945^{* *}$ & $0,839^{* *}$ & $0,714^{* *}$ \\
\hline & Sig. (bilateral) & & 0,665 & 0,272 & 0,000 & 0,000 & 0,000 \\
\hline & $\mathrm{N}$ & 156 & 156 & 156 & 156 & 156 & 156 \\
\hline \multirow[t]{3}{*}{ Accesibilidad } & $\begin{array}{l}\text { Correlación de } \\
\text { Pearson }\end{array}$ & 0,035 & 1 & $-0,397^{7^{*}}$ & 0,031 & 0,038 & $-0,095$ \\
\hline & Sig. (bilateral) & 0,665 & & 0,000 & 0,701 & 0,641 & 0,238 \\
\hline & $\mathrm{N}$ & 156 & 156 & 156 & 156 & 156 & 156 \\
\hline \multirow[t]{3}{*}{ Disponibilidad } & $\begin{array}{l}\text { Correlación de } \\
\text { Pearson }\end{array}$ & 0,088 & $-0,397^{* *}$ & 1 & 0,139 & 0,117 & $0,227^{* *}$ \\
\hline & Sig. (bilateral) & 0,272 & 0,000 & & 0,083 & 0,144 & 0,004 \\
\hline & $\mathrm{N}$ & 156 & 156 & 156 & 156 & 156 & 156 \\
\hline \multirow[t]{3}{*}{ FC } & $\begin{array}{l}\text { Correlación de } \\
\text { Pearson }\end{array}$ & $0,945^{* *}$ & 0,031 & 0,139 & 1 & $0,906^{* *}$ & $0,786^{* *}$ \\
\hline & Sig. (bilateral) & 0,000 & 0,701 & 0,083 & & 0,000 & 0,000 \\
\hline & $\mathrm{N}$ & 156 & 156 & 156 & 156 & 156 & 156 \\
\hline \multirow[t]{3}{*}{ NC } & $\begin{array}{l}\text { Correlación de } \\
\text { Pearson }\end{array}$ & $0,839^{* *}$ & 0,038 & 0,117 & $0,906^{* *}$ & 1 & $0,828^{* *}$ \\
\hline & Sig. (bilateral) & 0,000 & 0,641 & 0,144 & 0,000 & & 0,000 \\
\hline & $\mathrm{N}$ & 156 & 156 & 156 & 156 & 156 & 156 \\
\hline \multirow[t]{3}{*}{ NR } & $\begin{array}{l}\text { Correlación de } \\
\text { Pearson }\end{array}$ & $0,714^{* *}$ & $-0,095$ & $0,227^{* *}$ & $0,786^{* *}$ & $0,828^{* *}$ & 1 \\
\hline & Sig. (bilateral) & 0,000 & 0,238 & 0,004 & 0,000 & 0,000 & \\
\hline & $\mathrm{N}$ & 156 & 156 & 156 & 156 & 156 & 156 \\
\hline
\end{tabular}


La soberanía alimentaria está fundamentada por el conocimiento tradicional a través de FC, NC y NR; se complementa con la disponibilidad, accesibilidad y utilidad de las 84 especies comestibles, evidenciadas por el conocimiento tradicional. Los resultados de la tabla 4 demuestran una correlación bilateral menor entre el acceso y disponibilidad, pero expresa, que es el producto de la práctica socialmente compartida entre la conservación y reproducción de la naturaleza a través del conocimiento tradicional ancestral suscripto en la proactividad de generar alimentos locales. La utilidad mantiene una fuerte correlación entre FC, NC y NR. Este resultado reafirma el complemento entre la soberanía y seguridad alimentaria, analizada desde la etnoecología.

La soberanía alimentaria fue evidenciada a través de la FC, NC y NR; por consiguiente, dada la premisa de la correlación entre la seguridad alimentaria y soberanía alimentaria se corrieron las variables en el modelo de regresión logística. La tabla 5 muestra que la disponibilidad es la única variable significativa con un nivel de $96 \%$, luego entonces es la principal variable en manifestar y pronosticar a la soberanía alimentaria tradicional de San Antonio Acahualco y está fundamentada principalmente por las 84 especies como parte del bienestar de la población nativa y con raíces ancestrales. El modelo de regresión logística excluyó las variables de acceso y utilidad.

Tabla 5. Regresión logística.

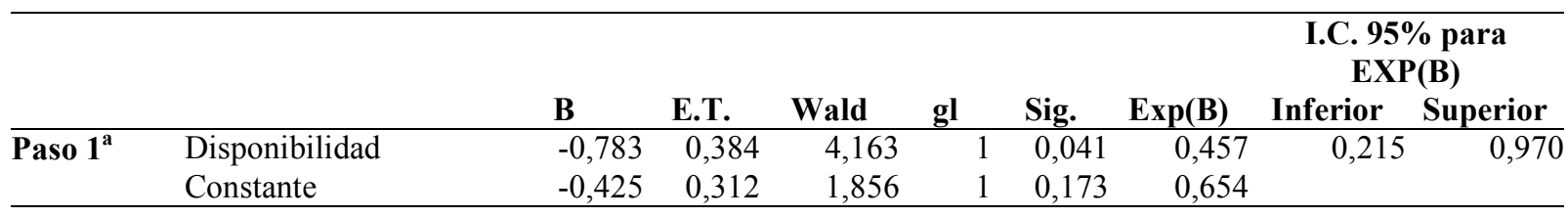

a. Variable(s) introducida(s) en el paso 1: Disponibilidad.

Una vez obtenidas las $b_{0}=$ constante de la tabla $5(\mathrm{~B}=-0.425)$ y $b_{1}=$ variable disponibilidad (B $=-0.783$ ). Los valores fueron sustituidos en la fórmula general de la regresión logística para identificar la probabilidad que ocurra la soberanía alimentaria $(\mathrm{Y})$ en San Antonio Acahualco a partir de la fuerte cohesión relacional de la disponibilidad, como variable explicativa, evidenciando la disponibilidad de especies comestibles disponibles durante todo el año codificada con el número 2; proporcionando como resultado el 33\% del bienestar alimenticio:

$$
P(Y)=\frac{1}{1+e^{(-0.425-0.783(2))}}=0.33
$$

La probabilidad que ocurra la soberanía alimentaria $(\mathrm{Y})$ en San Antonio Acahualco es a partir de la fuerte cohesión relacional de la disposición de especies estacionales (codificada con el número 1) de los meses de junio a octubre; resulta ser de $41 \%$ de probabilidad, al incrementarse las especies estacionales se solidifica la alimentación de las personas que poseen el conocimiento tradicional:

$$
P(Y)=\frac{1}{1+e^{(-0.425-0.793(1))}}=0.41
$$

La disponibilidad de aquellas especies que están presentes solo por temporada incrementa significativamente en un 0.8 y si sumamos las especies que se tienen durante todo el año y en temporada alcanza el 0.74 , más de la mitad de la unidad, es decir, casi el $100 \%$ de tener alimentos locales y que se caracterizan por ser nutritivos e inocuos. 


\section{DISCUSIÓN}

La esencia de la etnoecología es el trinomio del kosmo-corpus-praxis (Barrera-Bassols \& Toledo, 2005), y de acorde a la presente investigación no existe una separación entre estos hechos, si se realiza uno, los otros dos están implícitamente.

El kosmo procede del latín cosmos que significa universo, y en griego significa orden y totalidad. Para la población que posee el conocimiento tradicional de San Antonio Acahualco evidenciaron que la rotación de la tierra es parte del orden del universo; y están pendientes de las fases de la luna, para la práctica de la milpa, la recolección de especies silvestres y la cría de animales de traspatio. Además, saben interpretar el firmamento, la posición de la luna, de las estrellas y de las nubes para la predicción del clima, es decir, establecen al principio del año y en cada estación si habrá lluvia, sequia, heladas, nevadas y viento en días casi exactos. También, interpretan el comportamiento de ciertas aves, insectos y roedores, como la tuza, ya que estas especies anuncian el estado del tiempo.

El corpus es la forma de cómo las culturas almacenan y clasifican información sobre la relación que existe entre su forma de vida y los ecosistemas naturales, puede ser en forma textual o muestras orales. Por ejemplo, en forma textual existen papiros y pinturas que relatan especies (herbáceas y fauna) medicinales, comestibles, ornamentales y culturales (Zepeda \& White, 2008). En forma oral, se observa cuando el conocimiento ecológico tradicional es trasmitido de generación en generación. Por ejemplo: el conocimiento ecológico tradicional que poseen los nativos de San Antonio Acahualco sobre el manejo y conservación de los recursos forestales no maderables y maderables, de esta actividad se identificó la etnomicología, dando lugar a la identificación de los hongos comestibles, medicinales, lúdicos y tóxicos, así como su época, lugar y hábitat de reproducción de los macromisetos, así como la identificación de su sabor y olor, sin dejar a un lado la forma de como son deshidratados y cocinados para el consumo en épocas estratégicas. Además, se evidenció el conocimiento ecológico tradicional sobre la milpa, a través de fechas para el inicio de fecundar la tierra, la asociación de especies estratégicas, las prácticas del laboreo, el cuidado de las fases del crecimiento de dichas especies. De esta práctica ecológica se deriva la etnoedafología, porque los entrevistados evidenciaron la clasificación de los tipos de suelos (arcilloso, tepetate, polvilla, fangoso, pantanoso y cenagoso) y como deben ser manejados para el éxito del crecimiento de especies estratégicas. También se identificó el conocimiento ecológico tradicional sobre la fauna silvestre y la domesticada como es el guajolote, porque saben como se debe empollar y el cuidado para lograr el éxito total de la eclosión de los huevos. Y de esta práctica ecológica tradicional se deriva la etnozoología, la cual establece los principios básicos para el manejo tradicional y reproducción de especies comestibles como aves y mamíferos nativos de México. Otra de las facetas del conocimiento ecológico tradicional es sobre la predicción del estado del tiempo de acuerdo al comportamiento de la luna, las estrellas, nubes, insectos, aves y roedores. En la investigación de campo también fue manifestado el conocimiento ecológico tradicional sobre las plantas útiles, porque conocen la ubicación exacta de las especies útiles, así como su hábitat, época, formas de preparación, dosis y tiempo de suministración, he aquí que se evidencia la etnobiología. El corpus local de San Antonio Acahualco es valioso para la conservación del bosque, la milpa y animales de traspatio, pero la presente generación lo desconoce.

La praxis consiste en practicar o desarrollar los conocimientos, saberes y creencias propias de las culturas. La palabra conocimiento se deriva del griego "cognoscere" y "gnosis" se va a manifestar como una relación entre objeto-sujeto. El objeto es el que determina, el sujeto es determinado, por lo tanto, el conocimiento es dinámico y creativo. En cuanto a la palabra creencia es una formación con sufijo latino-entia (encia, cualidad de un agente, actividad) a partir del verbo creer, y este viene del latín credere (poner confianza en, creer, confiar en). La creencia es una cualidad del ser humano en el momento que interacciona en un núcleo social a través de prácticas socializadas y que resultan ser validas, siempre y cuando no alteren el orden, la convivencia y el bienestar. El conocimiento y las creencias confluyen en el conocimiento 
ecológico tradicional; su validez y veracidad está fundamentado en la observación, análisis e interacción con el medio natural, en consecuencia, éste se ha acumulado en diferentes áreas de interacción; como la etnomicología, etnozoología, etnoedafología y etnobiología. El conocimiento ecológico tradicional se desarrolla en forma ordenada, nace a partir de la estrecha relación entre pequeños grupos comunitarios y en los diferentes ecosistemas. Este conocimiento se valida a través de la forma de como identifican y manejan los recursos naturales, es decir, al identificar las características ecológicas del hábitat de las especies útiles y la reproducción de dichas características ecológicas en espacios denominados como la milpa, huertos, solares y patios en México. Sobresale el manejo de especies silvestres sin comprometer su continuidad, dejan semillas, flores y solo utilizan cantidades específicas. Las especies silvestres las clasifican de acuerdo a su forma, olor, sabor y utilidad. Colectan las especies silvestres de acuerdo a la época y en lugares específicos. El conocimiento ecológico tradicional tiene un grado de validez a través de las prácticas sustentables, que por miles de años se han practicado.

Históricamente San Antonio Acahualco tiene un registro como pueblo indio para el año de 1564 (Montes de Oca, 2004), se narra que su alimentación estaba sostenida a partir de la práctica de la agricultura, animales de traspatio y la recolección de especies silvestres comestibles. Esto se refleja a través del registro de especies comestibles silvestres en las tablas 1, 2 y 3 , que por cientos de años han alimentado a la población nativa de San Antonio Acahualco. Sin embargo, en la actualidad dichas especies están siendo desplazadas por otros alimentos; que se duda de su aporte a la nutrición y a la salud. Prueba de esto es que la población que posee el conocimiento tradicional mencionó que día a día se incrementa el número de personas que presentan sobrepeso y diabetes.

El conocimiento tradicional ecológico era imprescindible para la vida diaria y se transmitía oralmente de generación en generación, en España su ocaso inició en la década de los cincuenta el siglo XX, a partir de la industrialización y el desarrollo económico, estos provocaron el abandono del campo, especialmente de las áreas marginales, con el abandono de muchas de estas prácticas, los conocimientos perdieron su interés para quien los practicaban, así que se dejaron de transmitir (Pardo de Santayana et al., 2012). En el caso de San Antonio Acahualco su población económicamente activa inició a laborar en la zona industrial de la Ciudad de Toluca en la década de 1960, relativamente se fue abandonado la práctica de la milpa, cría de animales y huertos. Sector que está en alto riesgo de perder su alimentación nutritiva y saludable, al mismo tiempo, corren el riesgo de sumarse a la estadística de la pobreza y marginación. Las tendencias son visibles, porque es un fenómeno compartido en los países en desarrollo, en tanto que la FAO afirma que en México la población de menores ingresos destina un $46 \%$ de sus ingresos a cubrir sus necesidades alimentarias, mientras la población con mayores ingresos destinan el 18\% de sus ingresos a la alimentación (FAO, 2008).

Las personas que poseen el conocimiento tradicional de San Antonio Acahualco aportaron información sobre el bienestar del ser humano, porque abordaron temas como la disponibilidad de especies por estaciones, la accesibilidad a las especies a través del manejo de ecosistemas naturales y milpa y por último la acotación de la utilidad de cada especie, cuando se le asigna una categoría (s) de uso, como la comestible; dando un total de 62 especies silvestres comestibles. Está es una característica primordial de los pueblos ancestrales, porque, cuando, ellos, domesticaron plantas y animales aportaron las bases de la dieta más variada de alimentos saludables y el mejor balance nutricional de variedades locales (Onofre \& Felicia, 2011).

La utilidad, accesibilidad y disponibilidad de los recursos silvestres y cultivados son parte del bienestar de la población con raíces ancestrales de San Antonio Acahualco. Variables que siempre han estado presentes en las culturas ancestrales. Además, se consideró el número de informantes que mencionó la especie (FC), el número de los diferentes usos secundarios (NC) y el número de reportes (NR), estas variables fueron la base para construir el modelo de correlación de Pearson. En donde la utilidad es la que más se correlaciona con la praxis del conocimiento tradicional. Posteriormente la regresión logística evidenció que la disponibilidad 
resultó ser explicativa y la que evidencia que sea una probabilidad de éxito la soberanía alimentaria, a la cual tienen derecho los pueblos a empoderarse de las condiciones de reproducción de alimentos locales inocuos y nutritivos a partir de los aspectos cultural, ecológico y económico, como lo es la etnoecología, porque su objeto de estudio es la forma de organización y apropiación de la naturaleza fundamentando el bienestar alimentario, ecológico y cultural por parte de los pueblos nativos de México (Rosset, 2003; Heinisch, 2013; Almeida \& Scholz, 2008). Las tablas 1, 2 y 3 son producto de la forma de cómo el ser humano se ha apropiado de la naturaleza. En otros términos, las comunidades rurales, no prescinden de sus culturas y menos aún de sus hábitos alimenticios (Almeida \& Scholz, 2008). Hábitos que están siendo modificados en San Antonio Acahualco, de manera que, es una tendencia peligrosa de alto riesgo a la inseguridad alimentaria y la desesperanza social. Ante este escenario es importante revalorar y retomar las formas tradicionales para la obtención de alimentos locales. Debido a que las familias tradicionales rotan entre sus fincas distintos cultivos, de las especies más importantes para la alimentación, como la judía que cultiva numerosas variedades, de esta forma hace frente a las cambiantes e irregulares condiciones meteorológicas y perturbaciones ambientales, pues al menos se obtiene cosecha de alguna de las variedades, la diversidad permite disponer de fruta todo el año, algunas variedades de manzana y pera se conservaban almacenadas y evitan la maduración completa hasta tres o cuatro meses después de haberse cosechado, además, de cocinar distintas variedades, siendo esta una forma de dar diversidad a la dieta y cambiar de textura, sabor y color en el plato, en otros términos en las comunidades tradicionales existe una preferencia cultural por la diversidad (Pardo de Santayana et al., 2012). Los pueblos nativos de México desarrollaron una dieta tradicional en donde el maíz y el frijol aportaron los aminoácidos esenciales para la síntesis de proteínas, así como el almidón, el cual es protector contra el cáncer, con el mestizaje genético y cultural se desfasó el equilibrio genético-ambiental ancestral; esto podría ser un factor de riesgo para el desarrollo de enfermedades crónicas (Román, Ojeda-Granados, \& Panduro, 2013), por consiguiente, se requiere de la recuperación de alimentos tradicionales locales, para San Antonio Acahualco, se suscriben en la conservación del bosque, la práctica de la milpa y animales de traspatio, teniendo como fundamento a la etnoecología en su trinomio kosmo, corpus y praxis. Este trinomio se puede analizar por medio de las variables que sustenta la soberanía alimentaria. La correlación de Pearson identificó la utilidad como significativa y la disponibilidad como explicativa (determinada por la regresión logística) (fig. 3). Ambas sustentan la conservación simbiótica entre la diversidad biológica y la cultura; que son mutuamente dependientes y geográficamente coexistentes (Nietschmann, 1992).

Como ya se ha mencionado la agricultura industrial hoy en día es un modelo agotado (Altieri \& Nicholls, 2013), por lo que se debe revisar otras alternativas de producción ecológicas, desde la visión de los pueblos ancestrales, porque ellos han desarrollado métodos ecológicos que superan las técnicas de la agricultura industrial, como los químicos, herbicidas, fungicidas, plaguicidas y la ausencia del uso de hidrocarburos. Todas las actividades de la milpa se realizan de forma manual; hay participación de la mano de obra familiar en el desarrollo de las actividades del campo, hay ausencia de químicos para el éxito de las semillas cultivadas, de modo que hay una rotación y asociación de cultivos, que enriquecen el suelo, además abonan la milpa con eses de los animales de traspatio. El conocimiento ecológico tradicional es el eje rector para asegurar alimentos y consolidar la soberanía alimentaria. Retomando las especies estratégicas de la milpa, en particular el maíz, es un grano considerado por las familias campesinas como el pan o sustento de todo el año. Cuando se presenta la sequía o la continuidad de lluvias hay preocupación por la cosecha del maíz, frijol, haba, calabaza y chilacayote. Además, añaden que la contaminación, la tala, el comportamiento individual y la inseguridad social están ocasionado cambios en el medio natural. Fenómeno que es concebido como un castigo, por alterar la madre naturaleza. Señalaron que, al dejar de practicar la milpa, hay pérdida de variedades de color de maíz, como el maíz ranchero y el maíz palomero. A pesar de esto, aún se cultivan 12 variedades de color de maíz, entre ellas se identificaron tres razas cacahuacintle, elotes cónicos y chalqueño. 


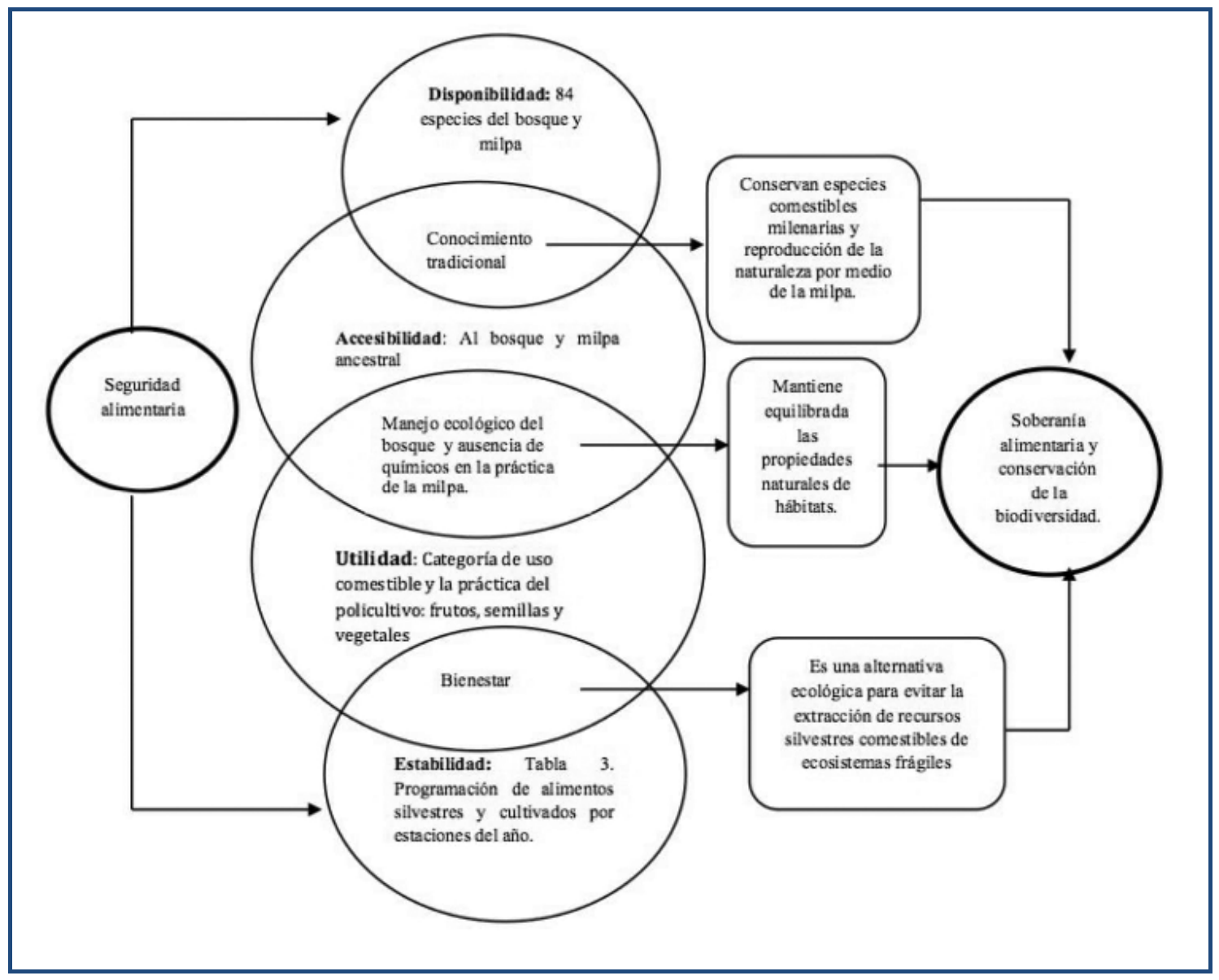

Fig. 3. Bases para gestionar el diseño de modelos de soberanía alimentaria y conservación de la biodiversidad.

\section{CONCLUSIÓN}

El estudio inició explorando el conocimiento tradicional o el conocimiento ecológico tradicional, y cada una de sus prácticas tienen un sentido contextual. El punto de partida fue el registro de la forma de como se maneja cada especie y su contextualización ecológica y cultural en San Antonio Acahualco. Esto permitió hacer un análisis detallado de la praxis del conocimiento tradicional, a través del listado de 84 especies, así como su uso comestible, su hábitat, su ciclo de vida y deshidratación para las estaciones en que no están disponibles en su ecosistema. Simultáneamente las personas que poseen el conocimiento tradicional relataron la importancia de las especies en su dieta, resaltaron la necesidad de conservar su hábitat y su praxis por medio de la milpa y animales de traspatio. A partir de este primer hallazgo se construyó la tabla 1 y 2, posteriormente se realizó un cuestionario estructurado con preguntas cerradas y codificadas, sobresaliendo la utilidad, accesibilidad, disponibilidad, FC, NC y NR (fig. 4). Luego entonces, esto permitió hacer el análisis, de que los pueblos ancestrales establecieron las bases de la seguridad y soberanía alimentaria a partir de la distinción de las especies comestibles silvestres y de la domesticación de aquellas que son estratégicas y que deben estar presentes durante todo el año, como es el maíz (tabla 3).

El desarrollo de la investigación de campo fue un proceso de aprendizaje continuo y que fue recuperado en el olvido e ignorado por la cultura actual. Las evidencias proporcionadas en la 
investigación permiten concluir que el conocimiento tradicional de los pueblos tiene el mismo nivel de importancia que el conocimiento científico, por lo tanto, se complementan, dando como resultado un análisis transdisciplinar que proporciona las bases para diseñar modelos que proporcionen alimentos locales a partir de la revaloración del conocimiento tradicional para que cada cultura conserve su propia soberanía alimentaria. Además, el conocimiento ecológico tradicional ofrece las bases del manejo de las especies comestibles en forma continua, sin comprometer su hábitat. La relación y apropiación que existe entre las personas que poseen el conocimiento tradicional y la naturaleza ha contribuido a su conservación y reproducción a favor del bienestar humano. El conocimiento tradicional de San Antonio Acahualco está anclado a un territorio configurado por el kosmo, corpus y praxis. Los resultados indican que si se preserva el conocimiento tradicional habrá conservación del bosque, la milpa y animales de traspatio, de lo contrario se incrementará la desesperanza, pobreza, marginación y el agotamiento de los recursos útiles del bosque y de la milpa de San Antonio Acahualco.

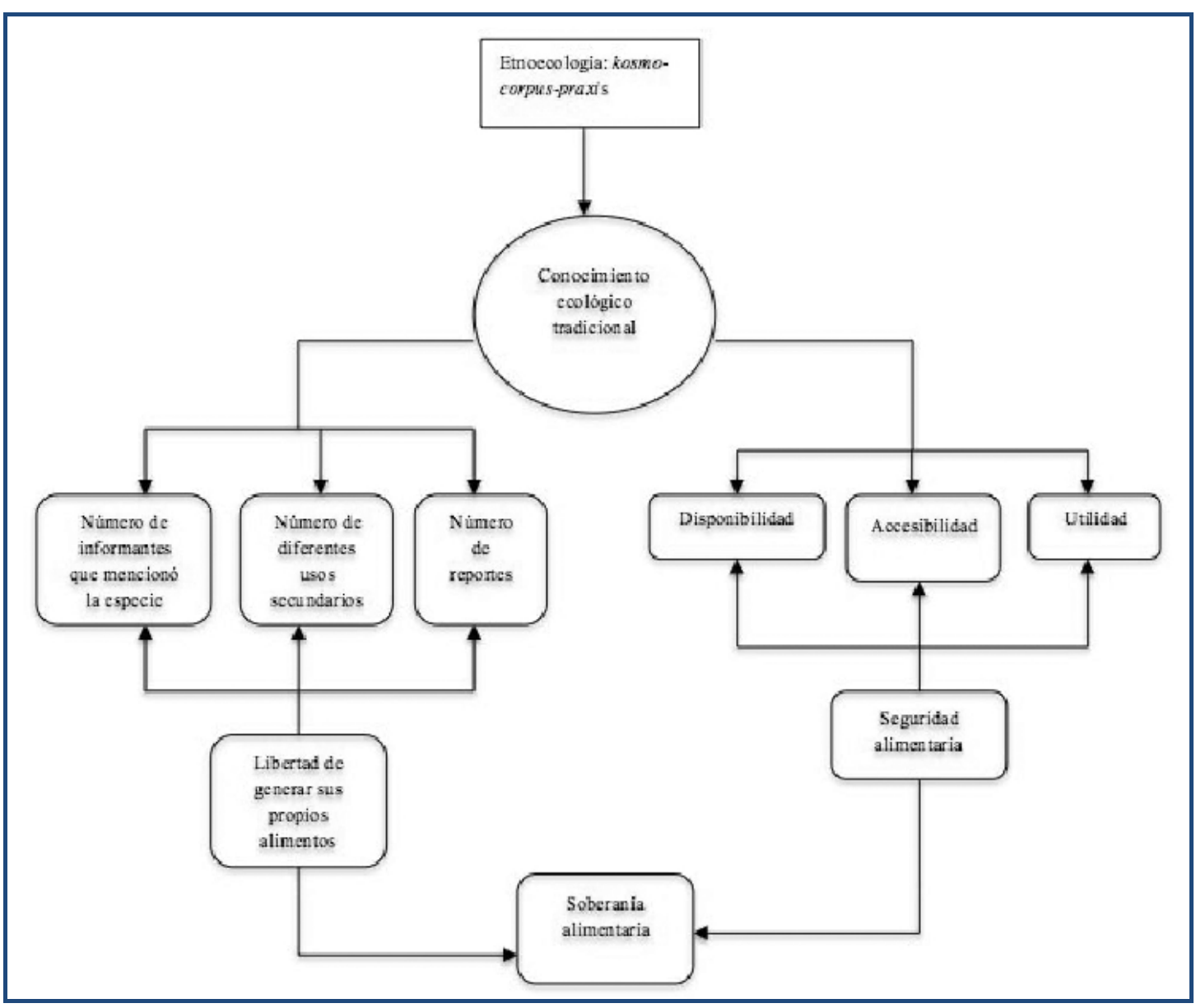

Fig. 4. Aporte del conocimiento tradicional sobre las variables de la seguridad y soberanía alimentaria. 


\section{LITERATURA CITADA}

Almeida, F. N. \& Scholz V. (2008). Soberanía alimentaria y seguridad alimentaria. Sociedade Brasileira de Economia, Administração e Sociologia Rural. Retrieved from https://www.google.com/search?q=Almeida+Filho+Niemeyer\%2C+Vera+Scholz. +200 8.+Soberanía + alimentaria $+\mathrm{y}+$ seguridad + alimentaria. + Sociedade+Brasileira + de + Econo mia\% $2 \mathrm{C}+$ Administração $+\mathrm{e}+$ Sociologia + Rural\&ie $=$ utf- $8 \& o e=u t f-8 \&$ client $=$ firefox-b

Altieri, M. A., \& Nicholls, C. I. (2013). Agroecología: única esperanza para la soberanía alimentaria y la resiliencia socioecologica. Agroecología. 7(2), 65-83. Retrieved from http://www.colby.edu/biology/BI402B/Al-

Barrera-Bassol, N. \& Toledo, V. M. (2005). Ethnoecology of the Yucatec Maya: Symbolism, knowledge and management of natural resources. Journal of Latin American Geography, 4(1), 9-41.

Bartra, A. (2008). Hacer milpa. Ciencias, (92-93), 42-45.

Cifuentes, B. J., Villegas, R. M. \& Pérez-Ramíre, L. (1986). Hongos. In Lot, A., Chiang F. (Compiladores), Manual de herbario. (pp. 55-64) Distrito Federal, México: Consejo Nacionalde la Flora. A. C.

FAO. (2008). Situación alimentaria en América Latina y El Caribe, en Observatorio del hambre en América Latina y El Caribe. Retrieved from http://www.observatoriodelhambre.net/

Gerez, P. \& Purata S. E. (2008). Guía práctica forestal de silvicultura comunitaria. Distrito Federal, México: SEMARNAT/CONAFOR/CCMSS.

Heinisch, C. (2013). Soberanía alimentaria: un análisis del concepto . In F. Hidalgo, P. Lacroix y P. Román (ed.) Comercialización y soberanía alimentaria (pp. 11-35). Quito, Ecuador: SIPAE. Retrieved from https://hal-agrocampus-ouest.archivesouvertes.fr/hal-00794380

INEGI. (2010). Censo de población y vivienda. Retrieved from www.beta.inegi.org.mx/ proyectos/ccpv/2010/

Leff, E. (2000). Espacio, lugar y tiempo: la reapropiación social de la naturaleza y la construcción local de la racionalidad ambiental. Desenvolvimento e Meio Ambiente, (1), 57-69.

Levy, T. S. I., Aguirre, R. J. R., Martínez, R. M. M., \& Durán, F. A. (2002). Caracterización del uso tradicional de la flora espontánea en la comunidad Lacandona de Lacanhá, Chiapas, México. Interciencia, 27(10), 512-520.

Montes de Oca, N. E. (2004). Los dueños y las tierras de la hacienda Santa Cruz de los Patos. Toluca, México: El Colegio Mexiquense A. C.

Nietschmann, B. (1992). The interdependence of biological and cultural diversity. Kemore, Center for World Indigenous Studies, (21).

Onofre, N. R. \& Felicia T. D. (2011). Agrobiodiversidad y desarrollo sostenible: la conservación in situ puede asegurar la seguridad alimentaria. Biocenosis, 24(1-2), 2129. Retrieved from www.cbd.int/decisions/cop/?m=cop-05

Pardo de Santayana, M., Morales, R., Aceituno, L., Molina, M., \& Tardío, J. (2012). El inventario español de los conocimientos tradicionales. Ambienta Retrieved from http://www.revistaambienta.es/WebAmbienta/marm/Dinamicas/secciones/articulos/Tr...

Pradilla, C. E. (1996). Teoría territorial: entre totalización y fragmentación. Ciudades, (29), 15-20.

Román, S., Ojeda-Granados, C. \& Panduro, A. (2013). Genética y evolución de la alimentación de la población en México. Revista de Endocrinología y Nutrición 21(1), 42-51.

Rzedowski, G. C. de, J. Rzedowski y colaboradores, 2005. Flora fanerogámica del Valle de México. Michoacán, México: Instituto de Ecología, A.C. y Comisión Nacional para el Conocimiento y Uso de la Biodiversidad.

Rosset, P. (2003). Soberanía alimentaria: reclamo mundial del movimiento campesino. Retrieved from: scola.co/wp-content/uploads/2014/Soberaniaalimentaria reclamoRosset.pdf.

Signorini, M. A., Piredda, M., \& Bruschi, P. (2009). Plants and traditional knowledge: An ethnobotanical investigation on Monte Ortobene (Nuoro, Sardinia). Journal of Ethnobiology and Ethnomedicine.Retrieved from https://doi.org/10.1186/1746-4269-5-6

Tafoya, E. (2012). Implicaciones de la tecnociencia en la modernidad reflexiva. Complejidad, riesgo y democracia. Mundo Nano, 5 (1). Retrieved from www.mundonano.unam.mx 
Recibido: $15 /$ febrero/2018

Aceptado: 10/diciembre/2018
Toledo, V. M., Boege, E. \& Barrera-Bassol, N. (2010). The biocultural heritage of Mexico: an overview. Landscape, (6), 6-10.

Toledo, V. M. (1990). La perspectiva etnoecológica. Cinco reflexiones acerca de las "ciencias campesinas" sobre la naturaleza con especial referencia a México. Ciencias (4), 22-29.

Trombulak, S. C., Omland, K. S., Robinson, J. A., Lusk, J. J., Fleischner, T. L., Brown, G., \& Domroese, M. (2004). Principles of conservation biology: Recommended guidelines for conservation literacy from the education committee of the society for conservation biology. Conservation Biology. Retrieved from https://doi.org/10.1111/j.15231739.2004.01851.x

Zepeda, G. C. \& White, O. L. (2008). Herbolaria y pintura mural: plantas medicionales en los murales del convento del Divino Salvador de Malinalco, Estado de México. Polibotánica, (25), 173-199. Retrieved from http://www.redalyc.org/articulo.oa?id $=62102513$. 